\title{
INVENTÁRIO DA AUSÊNCIA EM "O ROSTO", DE AMILCAR BETTEGA BARBOSA
}

\author{
INVENTORY OF ABSENCE IN "O ROSTO", \\ BY AMILCAR BETTEGA BARBOSA
}

Raul da Rocha Colaço'

Brenda Carlos de Andrade ${ }^{2}$

Resumo: Neste trabalho, buscamos investigar o tema da ausência no conto "O rosto", de Amilcar Bettega Barbosa (2002). Em outros termos, apreciamos a condiçâo de ausência em seus distintos níveis, considerando-a como um fator essencial para o desequilíbrio do protagonista da narrativa, que, devido à privaçáo de convívio humano e por sua ociosidade, concentra todos os seus esforços na captura de um rosto sem corpo que irrompe em sua residência. Para auxiliar essa análise, sáo úteis os mananciais de Remo Ceserani (2006), pela apresentaçáo dos sistemas temáticos recorrentes na literatura fantástica; de Louis Vax (1965), por designar as partes separadas do corpo humano como um dos temas da literatura fantástica; de David Roas (2014), por discutir as diferenças entre o fantástico e o grotesco; e de Rosalba Campra (2016), por debater a questăo da ausência, do silêncio, do năo dito e dos vazios da obra fantástica. Como resultado, constatamos que essa experiência insólita, em vez de trazer conforto ao protagonista, instaura o desamparo, pois esse personagem finda perdendo, com a evasăo do rosto, năo só o contato com o diferente (o Outro), mas também a própria identidade, tornando-se um ser ausente de si mesmo.

Palavras-chave: Ausência. Forma do nada. Amilcar Bettega Barbosa. Fantástico.

Abstract: In this paper, we aim to investigate the theme of absence in the short story " $O$ rosto", by Amilcar Bettega Barbosa (2002). In other terms, we examine the condition of absence in its different levels, considering it as an essential factor of the unbalance of the narrative protagonist, who, due to deprivation of human conviviality and his idleness, concentrates all of his efforts on the capture of a face without a body bursting into his residence. To support this analysis, the profitable work of Remo Ceserani(2006) will be useful for presenting the recurrent thematic systems in fantastic literature;

1 Mestrando em Teoria da Literatura pela Universidade Federal de Pernambuco (UFPE), onde realiza a pesquisa "As ruínas circulares de Amilcar Bettega Barbosa e de Murilo Rubiăo". E-mail: rauldarochacolaco@gmail.com.

2 Professora Adjunta de Literatura de Língua Espanhola na Universidade Federal Rural de Pernambuco (UFRPE) e Professora Colaboradora no Programa de Pós-Graduaçáo em Letras da Universidade Federal de Pernambuco (UFPE). E-mail: brenda.carlosdeandrade@gmail.com. 
as well as work of Louis Vax (1965), for designating the separate parts of the human body as one of the themes of fantastic literature; also the work of David Roas (2014), for discussing the differences between the fantastic and the grotesque; and the work of Rosalba Campra (2016), for debating the question of absence, silence, unsaid and voids in fantastic literature. As a result, we founded that this uncommon experience, instead of bringing comfort to the protagonist, establishes abandonment, since this character ends up losing, with the avoidance of the face, not only the contact with the different (the Other), but also his own identity, becoming a self-missing being.

Keywords: Absence. Shape of nothingness. Amilcar Bettega Barbosa. Fantastic.

- Croyez-vous aux fantômes?

- Non, mais j'en ai peur.

Mme Du Deffand à son ami Horace Walpole. ${ }^{3}$

A leitura da epígrafe nos apresenta um problema cabal: como pode uma pessoa temer algo que acredita náo existir? Essa pergunta, que fundamenta a obra A filosofía do horror ou paradoxos do coraçâo, do norte-americano Nöell Carroll (1999), por mais que seja realizada com vistas ao estudo do horror e dos seus efeitos em produçóes ficcionais, também pode ser estendida ao exame de uma criatura de difícil classificaçâo como o fantasma.

Temer a possibilidade de irrupçâo de um ser imaterial dentro de um mundo que se pauta em matéria é, certamente, mais duro e mais assustador do que a concretude imagética de uma presença incorpórea em nossa realidade. Em outras palavras, nâo sâo os espectros em si que nos assustam, mas a contingência de constatar o nosso evidente fracasso em entender e em dominar inteiramente o planeta que habitamos, deparando, entâo, com a fragilidade de nossas leis científicas e racionais.

É nessa esteira que se debruça a categoria estética do fantástico, revelando, segundo elucida o teórico espanhol David Roas, "a complexidade do real e a nossa incapacidade para compreendê-lo e explicá-lo" (ROAS, 2014, p. 104). Nesse contexto, podemos salientar que o escritor gaúcho Amilcar Bettega Barbosa, autor da narrativa a ser apreciada neste artigo, buscará despedaçar nossas certezas tanto em relaçầo à intrusăo súbita de um elemento sobrenatural num mundo idêntico ao real (leia-se: um espaço semelhante ao que experimentamos no dia a dia, àquilo que consideramos ser plausível no cotidiano), quanto à condiçăo impalpável de uma assombraçăo. ${ }^{4}$

3 - A senhora acredita em fantasmas? - Nâo, mas tenho medo. Senhora Du Deffand a seu amigo Horace Walpole (traduçâo nossa).

4 Nas linhas iniciais do primeiro capítulo de Territórios da ficçāo fantástica, Rosalba Campra (2016) discute uma pequena história em que o sumiço de um ser em determinado local torna-se a prova da sua condiçấo fantasmática. Na narrativa curta de Bettega Barbosa, temos um duplo jogo: o vidro quebrado da janela funciona como vestígio da apariçáo do rosto na residência do protagonista (ou seja, a visagem, diferentemente do que esperaríamos, é feita "de carne e osso"); e a ausência desse rosto na casa, logo após sua fuga, é mais potente, em efeitos aterrorizadores, do que a sua presença. 
Assim sendo, partimos para a análise do conto intitulado "O rosto", presente na obra Deixe o quarto como está (2002), e topamos, já na frase inaugural do texto, com a situaçâo insólita central enfrentada pelo narrador autodiegético: a presença de um rosto sem corpo a vagar pelos corredores da sua casa. Em outros termos, o narrador inicia seu relato a partir do momento em que ocorre a violaçáo da sua "intimidade protegida" (BACHELARD, 1993, p. 199), ou seja, da apariçăo inesperada de um ser indesejado em seu espaço de segurança e de conforto, conforme podemos ver a seguir:

Sempre morei na casa, mas só há pouco dei para vê-lo por aí, esquivando-se num văo de porta ou escapando por algum corredor. Náo sei quanto tempo ele esteve me observando ou mesmo me perseguindo pela casa. No fundo ele se aproveitou da minha ingenuidade, dessa maneira um pouco irresponsável de pensar que dentro da casa eu estaria livre de qualquer ameaça. Só que agora inverti o jogo. Sou eu quem o persegue, e náo estou para brincadeiras. Ele deve ter percebido, tenho certeza de que está com medo (BARBOSA, 2002, p. 71).

Nesse sentido, já nos é válido ressaltar que o protagonista da narrativa fantástica é, quase sempre, "[...] um homem comum, que năo apresenta características do herói, ao contrário, é singularmente vazio em relaçăo a seus caracteres" (CAMARANI, 2014, p. 120). Dito de outro modo, no trecho acima (e, por extensăo, em todo o texto), o personagem principal nâo descreve a si mesmo, isto é, a sua representaçăo física é definida justamente pela sua ausência, permitindo, assim, que qualquer leitor se reconheça por meio dos seus dilemas. Inclusive, sequer sabemos o nome do protagonista, que náo se identifica em nenhum momento, o que caracteriza mais uma ausência.

Por outro lado, em relaçăo às caraterísticas psíquicas, o narrador nos deixa pistas para que, após montarmos todo o quebra-cabeça, consigamos esboçar seus traços mentais. Noutras palavras, é através de seus atos que nos é possível mapear seus contornos psicológicos, ou seja, é quando passa a perseguir a assombraçáo que percebemos que o protagonista pode ser compreendido como uma entidade tăo absurda quanto o rosto que ronda a casa, na medida em que o homem altera a lógica esperada pelo leitor: ele năo é atemorizado pela apariçăo, mas sim quem a caça ${ }^{5}$.

Além disso, ainda podemos destacar a solidâo vivenciada pelo protagonista no que diz respeito ao confronto com objeto insólito: o homem segue no encalço do rosto sem qualquer companhia ou ajuda de outrem, dependendo exclusivamente dos seus esforços para restaurar a ordem do seu lar. Nesse sentido, é relevante apontarmos que "a aventura fantástica é quase sempre uma aventura solitária. A solidăo fantástica năo se refere apenas a um isolamento objetivo: é a negaçăo da comunidade humana" (CAMARANI, 2014, p. 52).

Dito de outra forma: o personagem principal é o único morador da casa (pelo menos até a chegada do rosto), aproveitando-se dessa condiçăo para, assim, isolar-se do convívio com outros humanos. Entăo, por ser naturalmente um solitário, dedica-se com afinco na caçada ao elemento invasor, o que repercute em duas frentes: por náo ter compromissos sociais, o narrador dedica-se inteiramente à perseguiçâo do rosto,

5 Aqui, desembocamos em outro traço comum aos protagonistas de narrativas fantásticas também sinalizado por Camarani (2014): a prática da presunçăo e da soberba, visto que ele se julga capaz de amedrontar uma assombraçăo. 
tornando essa aventura o objetivo de sua vida; e, por dedicar-se integralmente a essa empreitada (e, possivelmente, por sentir-se só), finda se acostumando com a presença da figura insólita em sua residência, criando, de certo modo, um apego em relaçấo a ela. ${ }^{6}$

Conforme elucida Remo Ceserani, na sua obra intitulada $O$ fantástico (2006), a apariçâo do estranho, do monstruoso, do irreconhecível é um dos sistemas temáticos recorrentes na literatura fantástica. Ainda segundo o autor italiano, "a cena da apariçăo repentina e inesperada de um estrangeiro no espaço doméstico de uma casa é quase um estereótipo [...]" (CESERANI, 2006, p. 84). Nesse fluxo, e, ao mesmo tempo, em contraposiçấo ao que poderia ser classificado como lugar-comum dos textos fantásticos, o narrador nos anuncia um novo desdobramento possivelmente afiliado à presença do elemento estrangeiro no ambiente domiciliar: a constante mutaçăo dos aposentos da casa. Nas suas palavras:

Náo sei quanto tempo disporei dessa sala. Assim como alguns cômodos brotam da noite para o dia, outros desaparecem sem explicaçâo nenhuma, numa espécie de balanceamento que a casa faz, como que possuída por um rigor matemático. Já pensei em encarcerar o rosto em uma das peças que estăo condenadas ao desaparecimento. Mas como descobrir quais sâo essas peças? Tenho intuiçôes, mas nâo basta (BARBOSA, 2002, p. 73).

Após algum tempo dedicando-se a capturar o rosto sem qualquer sucesso, o protagonista encara uma nova adversidade: a alteraçăo constante dos cômodos de sua residência. Nessa perspectiva, a casa, que deveria ser um local familiar ao seu dono, torna-se um ambiente hostil na medida em que se transmuta constantemente, fator que năo permite a memorizaçăo das suas divisóes. Em outros termos, ao atualizar-se com recorrência, a casa transforma-se num espaço desconhecido ao personagem principal, isto é, torna-o estrangeiro num ambiente que lhe deveria ser de intimidade, de conforto. E, retomando os apontamentos de Remo Ceserani,

A súbita intrusâo de um personagem que possui as características culturais de um estrangeiro, dentro do espaço reservado e protegido que pertence a uma família e a uma comunidade restrita, torna-se pleno de aspectos inquietantes, suscita reaçóes de profunda perturbaçăo psicológica e năo tem como consequência a simples exclusăo do elemento estranho (CESERANI, 2006, p. 84).

Ou seja, é a partir da invasâo do rosto no espaço doméstico que a casa abandona sua fixidez arquitetônica para se constituir através de movimentos incessantes. Em suma: é a chegada do estrangeiro que modifica a dinâmica da casa na medida em que transforma o espaço e o protagonista em instâncias estranhas entre si, destroçando, assim, a relaçâo de familiaridade outrora existente; e, uma vez arruinado esse vínculo íntimo e afetivo, é praticamente impossível restaurá-lo.

Portanto, será nesse ambiente em constante mutação que o protagonista perseguirá

6 Dentre as várias classificaçôes de apariçăo oferecidas por Valter da Rosa Borges (2001) em seu livro intitulado Fenomenologia das apariçōes, uma nos é sobressalente: a que é percebida por apenas uma pessoa. Como só existe um único ser humano que entrou em contato com aquele espectro, temos uma certa desconfiança para atribuir um valor de verdade a essa experiência. Sendo assim, estamos no território do fantástico, pois: oscilamos entre a presença real do insólito na diegese e a loucura do personagem que pode ter inventado essa fantasia para se ocupar; há uma crise entre o que é ou nâo possível de acontecer tanto na narrativa quando no mundo em que vivemos; há uma fissura no nosso conceito de realidade. 
o rosto que deveria assombrá-lo, elemento que se converte em mais uma dificuldade para a realizaçấo de sua incansável tarefa. Numa dessas tentativas de capturar a apariçâo, o homem a encurrala num corredor desconhecido:

Quase consegui, há poucos dias, quando o acossei através de um longo corredor. Era um corredor por onde eu nunca havia passado. De repente, lá estava ele à minha frente: aquele ponto negro no ar, seus cabelos voando, indo de uma parede à outra do corredor à procura de uma porta aberta por onde escapar. A intervalos ele olhava para trás, girando a cabeça como se tivesse um pescoço que a sustentasse e um obro sobre o qual girar. Pude ver o terror nos seus olhos, a boca entreaberta pelo esforço e pelo medo (BARBOSA, 2002, p. 73-74).

Nesse excerto, o personagem principal se defronta, pela primeira vez, com a possibilidade de contemplar o rosto que invadiu sua casa. E, apesar de a assombraçấo ser caraterizada com traços anômalos (ser formada por apenas um ponto negro, girando sobre um eixo inexistente), o homem parece năo se perturbar com essa visâo.7 De forma inversa ao esperado pelo leitor, é a figura invasora quem se assusta com os atos de coragem do protagonista.

Mas, apesar da situaçăo ser propícia à captura do rosto, ocorre uma reviravolta:

Ele buscava uma saída qualquer, e aquele ziguezaguear entre as paredes do corredor me lembrou uma mosca desatinada numa tarde abafada de verăo. Foi o que o salvou, daquela vez. Năo suportei a comicidade de minha associaçáo. Ora, onde eu fora buscar aquela imagem de mosca atordoada se o rosto era tăo maior e tâo mais perigoso? Comecei a rir e năo consegui continuar a perseguiçấo. Fui obrigado a sentar no chăo e me encostar na parede e assim, sentado, gargalhando, deitando lágrimas de tanto rir, ainda vi o último olhar que ele me lançou antes de sumir por uma porta à esquerda. Foi quando consegui parar de rir. E meu corpo tremia inteiro e os dentes rangiam como se tivessem lixas nas pontas (BARBOSA, 2002, p. 74).

Após inúmeras tentativas sem sucesso, o protagonista, enfim, conseguiu cercar o invasor de modo a deixá-lo sem possibilidade de fuga. No entanto, os movimentos desajeitados e desesperados do rosto, ao serem associados às agitaçóes de uma mosca, desencadearam uma crise de riso no homem, ato desgovernado que o impediu de concretizar seu tâo almejado objetivo. Nessa perspectiva, podemos salientar que há aqui uma apropriaçâo do grotesco na medida em que "o grotesco, por sua vez, é uma categoria estética baseada na combinaçâo do humorístico com o terrível" (ROAS, 2014, p. 190).

Isso implica dizer que o riso excessivo do personagem principal é fundamental para demarcar sua tentativa de diminuir o impacto da visăo estranha com que se confronta, de torná-la ridícula e insignificante aos seus olhos; por outro lado, esse rir desenfreado também está associado à tensâo da situaçâo, isto é, o riso se origina do nervosismo e do

7 Jean-Paul Sartre, em "Aminadab, ou o fantástico considerado como linguagem" (2005), ao confrontar os protagonistas de $\mathrm{O}$ castelo, de Franz Kafka, e Aminadab, de Maurice Blanchot, indica que ambos nunca se espantam com nenhum evento, tudo lhes parece natural, argumento que findou se estabelecendo como espanto congelado. Essa postura está também presente no protagonista de Amilcar Bettega Barbosa do conto ora analisado. Nessa senda, "eis-nos coagidos, pelas próprias leis do romance [ou do conto], a adotar um ponto de vista que náo é o nosso, a condenar sem compreender e a contemplar sem surpresa o que nos deixa pasmos" (SARTRE, 2005, p.144). 
descontrole frente ao inesperado, frente à incapacidade do personagem de agir racionalmente diante da situação insólita vivenciada.

Ainda na esteira de David Roas, é importante destacarmos que "essa sensaçâo [de tomar consciência da nossa superioridade e rir] dura muito pouco, o tempo que demoramos em perceber que na verdade esses outros somos nós, que esse outro mundo nâo passa de um reflexo deformado do nosso [...]" (ROAS, 2014, p. 203, grifos do autor). Ou seja: o estado físico e psicológico em que se encontra o protagonista após a evasâo do rosto nos revela a incongruência de rir das próprias limitaçōes e incompetências, a funesta comicidade de rir da própria desgraça.

Em adiçăo a isso, se quisermos expandir nossa leitura para outras significaçôes, cabe recorrer a Louis Vax, no momento em que esclarece que "la mano, el ojo, el cerebro, constituyen precisamente las partes nobles del cuerpo humano; son los órganos que permiten al hombre actuar, ver, organizar; y son justamente los que producen inquietud cuando se perturba su normal funcionamiento"8 (VAX, 1965, p. 28). Em outras palavras, o fato de a assombraçăo ser um rosto deslocado de suas funçôes comuns e, mais além, de um corpo junto ao qual deveria estar interligado, incomoda o personagem principal ao passo que essa presença insólita pode funcionar como profecia para sua futura condiçâo, ou seja, ao visualizar um rosto vagando sozinho pelos corredores de sua residência, o protagonista, mesmo a contrapelo, poderá cogitar um destino semelhante para si.

Algum tempo depois dessa tentativa frustrada de captura do rosto, o protagonista, enfim, consegue aprisioná-lo numa gaiola. É a partir desse instante que o homem passa a demonstrar uma certa afeiçăo para com o encarcerado, tratando-o, de certo modo, como um animal de estimaçấo, ou seja, passando dias e noites a contemplá-lo e a dedicar-lhe cuidados. Num desses momentos, o narrador autodiegético

estava pousando a tigela cheia de leite dentro da gaiola quando sua voz me pegou inteiramente de surpresa. Era a primeira vez que ele falava alguma coisa e, além disso, me olhava duramente nos olhos. Era uma voz fina e meiga, mas incisiva.

- Você pode trazer uma toalha para enxugar minha boca?

Minha máo tremeu e deixei entornar um pouco de leite no assoalho da gaiola. Olhei para ele sem saber o que dizer, e fui buscar a toalha imediatamente (BARBOSA, 2002, p. 79).

Nesse excerto, podemos salientar que o rosto, mesmo estando engaiolado, é quem tem autoridade sobre o homem. Sendo assim, se recuperarmos toda a trajetória que foi percorrida pelo protagonista até agora, percebemos, rapidamente, que o homem tornou-se escravo do seu desejo de capturar o forasteiro que invadiu sua casa, abdicando de todas as outras atividades que provavelmente dispunha. Nessa senda, a própria ausência de resposta verbal ao pedido do rosto reforça o caráter dominador do invasor: o homem, psicologicamente abalado, obedece seu pedido imediatamente.

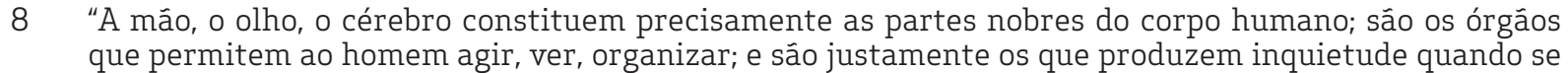
perturba seu normal funcionamento" (traduçăo nossa). 
Em acréscimo, é pela ausência que o rosto manipula o protagonista, ou melhor: é quando o protagonista vai buscar o ausente que sua vida entra em ruína. Ao tentar atender o pedido do rosto sem raciocinar sobre as possíveis consequências desse ato, o homem acaba por oferecer a oportunidade de fuga tăo esperada pelo prisioneiro:

Quando estava no meio do corredor ao lado da saleta foi que me dei conta da sua jogada de esperteza. Quase ao mesmo tempo, ouvi o estouro do vidro. Voltei correndo, mas era tarde demais. Lá estava a gaiola com a porta aberta, a porta que, na minha atrapalhaçăo, eu esquecera de fechar. E o vidro da janela com um buraco redondo no meio.

Aquela imagem da gaiola vazia, com a portinhola escancarada, ao lado do vidro quebrado da janela e os cacos espalhados sobre a mesa, aquela imagem se grudou à minha mente como uma pele, uma membrana viscosa e quente que até hoje está em mim. De imediato, a imagem me transmitiu tristeza. A combinaçăo dos cacos de vidro com a portinhola aberta e a gaiola de arame vazia, tudo me encheu de uma tristeza gorda e sincera, que me deixou estagnado.

Depois o sentimento foi se transformando em incerteza, apreensăo e, finalmente, medo (BARBOSA, 2002, p. 79).

O vazio deixado pela ausência do rosto dentro da gaiola e, por extensấo, dentro da casa, gera um abalo na alma do personagem principal, que passará a sentir-se só como nunca. Esse sentimento de abandono ou de solidáo é algo comum a qualquer protagonista de narrativas fantásticas, pois esse tipo de personagem costuma ser "solitário [...] entre dois mundos - o do fenômeno e o do real diegético" (CAMARANI, 2014, p. 120).

Dito de outra maneira, o homem encontra-se exilado numa espécie de entre-lugar, pois năo pertence ao mundo insólito da apariçăo que surgiu em seu lar (ou seja, é simplesmente um homem comum frente a um ser extraordinário), mas também nâo se integra ao mundo real, ao convívio com outros homens. Em resumo: o protagonista sofre com a ausência do fenômeno que o ocupou por vários dias, assim como sofrerá pela falta de proximidade com seus semelhantes.

Nesse curso, "a apariçăo do fenômeno teria por funçăo revelar ao personagem seus próprios limites; daí em diante, sozinho diante do fenômeno, tenta voltar-se para os outros, mas sem poder sair da situaçăo inicial de solidâo, choca-se com a incompreensăo e vê-se excluído ou rejeitado" (CAMARANI, 2014, p. 120). É dizer: o ato de contar sua história é o meio que o narrador encontra para procurar ajuda (que nunca chegará) e para aproximar-se do(s) outro(s) e sentir-se menos solitário. Entretanto, qualquer açâo que empreenda sempre tende à ausência, à solidāo infinita, o que resulta num rechaço até da assombraçấo, que o abandona.

Nessa vereda, recorremos, novamente, a Gaston Bachelard, quando elucida que "em nossas casas grudadas umas às outras, temos menos medo. A tempestade sobre Paris náo tem contra o sonhador a mesma capacidade ofensiva que contra a casa de um solitário" (BACHELARD, 1993, p. 215). Isso significa dizer que, por ser sozinho e por năo poder contar com nenhum auxílio senáo o próprio, o sentimento de desamparo se intensifica no seio do personagem. ${ }^{9}$

9 Nas palavras de Georg Lukács, em A teoria do romance (2009), “cada uma terá que nascer da solidâo e, 
Em adiçăo a isso, Ana Luiza Silva Camarani, ao comentar sobre a obra La séduction de l'étrange, de Louis Vax, declara que “ $O$ 'sujeito' de uma aventura fantástica é sempre o herói-vítima; seu "objeto" é sempre o monstro. Mas esse objeto que ameaça o sujeito é uma parte revoltada dele mesmo [...]" (CAMARANI, 2014, p. 52).

Tal afirmaçâo deságua na compreensâo de que o rosto, de algum modo, modifica a identidade do protagonista desde o primeiro contato, ou seja, o Eu do protagonista começa a se esvanecer à medida em que recebe a influência do Outro invasor (aqui nos referimos ao que acontece de forma involuntária, mais precisamente aquilo que toca a inversăo de papéis entre ambos: o homem, no início da narrativa, exalava frieza, enquanto o rosto era quem estava amedrontado; com o passar do tempo, as posturas se opóem); à medida em que o objeto-monstro passa a controlar o herói-vítima; e à medida em que o homem abdica da sua personalidade para converter-se, por imitaçáo, no Outro estrangeiro para evitar a solidâo.

Nesse fluxo, o trecho a seguir abarca os últimos instantes da tentativa de conversâo do protagonista no rosto que invadiu sua residência:

\begin{abstract}
Imaginei que, adotando a sua forma de ser e agir, poderia atraí-lo. Dia desses resolvi descer a escada do mesmo jeito que ele. Abracei as pernas, pus a cabeça entre os joelhos, enrosquei-me todo e desci. Cheguei a pular uns dois ou três degraus como se fosse mesmo uma bola de gude, mas năo consegui manter a posiçăo e rolei escada abaixo. Acho que quebrei um braço porque me dói muito e já năo consigo mexê-lo. Pensei em inspecionar lá fora, pois ele bem poderia andar ali pelo jardim. Usando o braço bom, consegui alargar o buraco do vidro e meti a cabeça através dele. Com a cabeça dentro do buraco, virei para o lado a fim de buscar uma visăo melhor, mas senti uma ponta do vidro rasgando meu pescoço. O filete de sangue desceu pelo pescoço até o peito. Virei para o outro lado e me feri ainda mais.
\end{abstract}

Agora sei que estou preso, que minha cabeça está presa lá fora. Cada movimento que faço complica as coisas. Mas năo estou desesperado. Estou triste, cansado, mas năo me sinto derrotado (BARBOSA, 2002, p. 80).

Para evitar a solidāo gerada pela ausência da apariçáo, o homem tenta imitá-la para fazê-la retornar à sua residência e, assim, sentir-se menos desamparado. ${ }^{10}$ No entanto, ao abdicar da sua natureza para imitar a do Outro, o protagonista deve apagar a si mesmo para que o Outro tenha espaço para entrar. Mais: para tornar-se o Outro, o homem precisa enfrentar um ritual de passagem: transformar-se, de fato, num rosto despregado do resto do corpo. ${ }^{11}$

na solidăo insuperável, em meio a outros solitários, precipitar-se ao derradeiro e trágico isolamento" (LUKÁCS, 2009, p. 43), trajetória essa que será cumprida à risca pelo protagonista do conto analisado.

10 Essa solidăo é marcada, ainda, pela ausência de fé do personagem. Năo tendo em quem ou no que acreditar (ou quem conversar ou em quem ou no que se apoiar etc.), o protagonista tende à cegueira. “E como ninguém se conhece a si mesmo, náo pode desde logo ser seu próprio guia; pede a sabedoria que náo empreendamos coisa alguma de importância sem tomar conselho, em espírito de submissăo e de humildade. Esta justa desconfiança de si próprio previne as quedas e purifica o coraçăo [...]" (ROQUETTE, 2013, p. 34).

11 Esse rosto inicial que prenuncia um rosto que será visto no futuro nos remete ao conto "Dos veces el mismo rostro", do autor argentino Vicente Barbieri (1960), no qual um homem se encontra em seu apartamento e, durante a noite, tem a visâo espectral de um rosto; meses se passam e o protagonista se encontra em repouso num hospital após realizar um procedimento cirúrgico, quando depara com a presença, em seu leito, de um visitante que possuía um rosto idêntico àquele que havia visto tempos atrás em seu quarto. 
No entanto, essa metamorfose finda incompleta (talvez pela impossibilidade do Eu de converter-se totalmente no Outro ou talvez para abrir uma ausência a ser suprida pelo leitor com seu repertório), isto é, o conto termina com o personagem principal preso na janela, com o rosto pendente ao lado de fora e o corpo para dentro. Sendo assim, é a ausência de soluçăo, ou seja, a ausência da conversăo total do homem no rosto, a sua permanência num espaço limítrofe entre o ser ordinário e o extraordinário que criam um gigantesco precipício para que o leitor decida se deve pular ou năo, um espaço nauseante tendente ao infinito, no qual o protagonista fica eternamente preso nessa condiçăo: eternamente ausente de si mesmo.

Nesse curso, retomando as contribuiçōes de Rosalba Campra, "o único que sugere abismos inextinguíveis é a ausência. Uma ausência da qual podemos suspeitar que nâo responde a uma vontade de ocultaçáo por parte do narrador, muito menos a sua ignorância, mas a vertigem da nâo significaçăo" (CAMPRA, 2016, p. 142). De modo mais detalhado, todas as ausências que se apresentam na narrativa confluem na direçâo de um fim comum: a denúncia da natureza opaca e obscura do evento insólito que o narrador presencia e, ademais, que pactua.

Dito de outra forma, o protagonista do conto de Amilcar Bettega Barbosa segue a trilha do narrador autodiegético de "Por los tiempos de Clemente Colling", do escritor uruguaio Felisberto Hernández, que

[...] tendré que escribir muchas cosas sobre las cuales sé poco; y hasta me parece que la impenetrabilidad es una cualidad intrínseca de ellas; tal vez cuando creemos saberlas, dejamos de saber que las ignoramos porque la existencia de ellas es, acaso, fatalmente oscura: y ésa debe ser una de sus cualidades.

Pero no creo que solamente deba escribir lo que sé, sino también lo otro ${ }^{12}$ (HERNÁNDEZ, 2009, p. 21).

É dizer: ao detalhar sua experiência relativa à intrusăo de um ser sobrenatural num mundo que conta, apenas, com as leis naturais para explicá-lo, o protagonista de "O rosto" é obrigado a reproduzir a face impenetrável desse evento insólito, visto que esta é componente indispensável para que se consiga esboçar um quadro fidedigno dessa vivência. Nessa senda, a ausência de convicçăo sobre variadas nuances do fato (como o rosto apareceu na casa?; qual era o seu objetivo ali?; por que foi embora?) só reforçam o teor de "nâo significaçăo" e de "nấo saber" contidos no objeto de observaçấo do narrador.

Ainda seguindo a argumentaçăo de Rosalba Campra, vemos que

o conto fantástico que instaura o terror graças aos seus próprios vazios joga com um terror năo exorcizável. Aquela mínima segurança tende a ser suplantada pela ausência de um inimigo. [...] O mundo pode ser inteiramente natural, inscrever-se em um sistema de realidade identificável, e, contudo, escapar à compreensăo. O herói fantástico já năo pode lutar, enfrenta uma forma do nada (CAMPRA, 2016, p. 142).

12 "[...]tereique escrever sobre muitas coisas sobreas quais sei pouco; eatéme parece que aimpenetrabilidade é uma qualidade intrínseca delas; talvez quando cremos sabê-las, deixamos de saber que as ignoramos porque a existência delas é, talvez, fatalmente obscura: e essa deve ser uma de suas qualidades. Porém nâo creio que somente deva escrever o que sei, mas também o outro" (traduçấo nossa). 
Portanto, através da leitura deste trecho, podemos admitir que é ao instaurar a ausência que se expande a desconfiança: esse abismo lacunar gera uma expectativa e uma suspensáo da tranquilidade do protagonista, pois náo saber o que esperar torna-o mais inseguro do que a certeza de que precisa exorcizar sua casa de uma assombraçăo. É aqui que a falta de estabilidade experimentada pelo personagem se estende ao leitor: ao deparar com um mundo fictício que se assemelha em muito à realidade física que compartilhamos, chocamo-nos com o espesso muro da incerteza ao nos certificar năo só da vulnerabilidade de nossa compreensăo das leis naturais, mas, especialmente, ao contemplar a inerente profundeza de seus vazios de significaçăo.

E esse vácuo deixado pelo texto promove, fundamentalmente, o inesgotamento de interpretaçóes: por se tratar de "uma forma do nada", tentamos preenchê-la (narrador e/ou protagonista e leitor) com diversas conjecturas plausíveis. Dessa maneira, só nos cabe concluir, assim como Rosalba Campra, que "o evento fantástico nâo atua como um elemento de fechamento, [...] mas como um gatilho que abre outras possibilidades: que exige outras leituras" (CAMPRA, 2016, p. 67). E a que fizemos aqui é apenas uma dentre as várias praticáveis.

\section{REFERÊNCIAS}

BACHELARD, G. A poética do espaço. Săo Paulo: Martins Fontes, 1993.

BARBIERI, V. Dos veces el mismo rostro. In: CÓCARO, N. (org.). Cuentos fantásticos argentinos. Buenos Aires: Emecé, 1960. p. 43-45.

BARBOSA, A. B. Deixe o quarto como está: estudos para a composiçăo do cansaço. Sâo Paulo: Companhia das Letras, 2002.

BORGES, V. da R. Fenomenologia das apariçóes. Recife: Ediçōes Bagaço, 2001.

CAMARANI, A. L. S. A literatura fantástica: caminhos teóricos. Sāo Paulo: Cultura Acadêmica, 2014.

CAMPRA, R. Territórios da ficçâo fantástica. Rio de Janeiro: Dialogarts Publicaçōes, 2016.

CARROL, N. A filosofia do horror ou paradoxos do coraçâo. Campinas: Papirus, 1999.

CESERANI, R. O fantástico. Curitiba: Editora UFPR, 2006.

HERNÁNDEZ, F. Por los tiempos de Clemente Colling. In: . Cuentos reunidos. Buenos Aires: Eterna Cadencia Editora, 2009. p.17-93.

LUKÁCS, G. Teoria do romance: um ensaio histórico-filosófico sobre as formas da grande épica. Săo Paulo: Duas Cidades: Editora 34, 2009. (Coleçăo Espírito Crítico) 
ROAS, D. A ameaça do fantástico: aproximaçōes teóricas. Săo Paulo: Editora Unesp, 2014. ROQUETTE, J. I. Reflexôes. In: IMITAÇĀO de Cristo. 30.ed. Embu - SP: Editora Ave-Maria, 2013. p.34.

SARTRE, J-P. Aminadab, ou o fantástico considerado como linguagem. In: Situaçōes I. Sâo Paulo: Cosas Naify, 2005. p. 133-149.

VAX, L. Arte y literatura fantásticas. Buenos Aires: EUDEBA, 1965.

Submetido em 17 de março de 2018 Aceito em 17 de maio de 2018 